\title{
Bevacizumab in the Management of Epithelial Ovarian Cancer
}

\author{
Maurie Markman, MD \\ Senior Vice President of Clinical Affairs, National Director for Medical Oncology, Cancer Treatment Centers of America, Philadelphia, US; \\ Clinical Professor of Medicine, Drexel University College of Medicine, Philadelphia, US
}

\begin{abstract}
Preclinical investigations have provided strong support for the hypothesis that angiogenesis is a potent driver of epithelial ovarian cancer progression. Phase II data have revealed the activity of single-agent bevacizumab in previously treated and clinically defined platinum-resistant ovarian cancer. Several reported phase III randomized trials, involving primary and both 'platinum-sensitive' recurrent and platinum-resistant disease, have demonstrated the addition of bevacizumab to a cytotoxic chemotherapy regimen improves progression-free survival compared with chemotherapy alone. While there continues to be considerable debate regarding the optimal dose, timing, and duration of bevacizumab administration in ovarian cancer, the existing data provide strong support for an important role for this agent in the overall management paradigm for this malignancy.
\end{abstract}

\section{Keywords}

Ovarian cancer, bevacizumab, anti-angiogenic therapy, antineoplastic therapy

Disclosure: Maurie Markman, MD, has served as a member of medical advisory boards for Genentech, Celgene, Amgen, GlaxoSmithKline, and Boerhinger Ingelheim. Received: August 9, 2013 Accepted: August 30, 2013 Citation: Oncology \& Hematology Review (US), 2013;9(2):129-131 DOI: 10.17925/OHR.2013.09.2.129 Correspondence: Maurie Markman, MD, 1425 Stocton Road, Meadowbrook, PA, 19046, US. E: maurie.markman@ctca-hope.co

Epithelial ovarian cancer has long been recognized as being highly sensitive to cytotoxic chemotherapy, with anticipated objective response to platinum-based chemotherapy of approximately 70-85 \%1. Furthermore, overall survival (OS) for women presenting with advanced disease has been documented to have improved over the past few decades, ${ }^{2}$ although unfortunately the majority of responding patients ultimately experience recurrence of their disease process and die of complications associated with progression of the malignancy.

As a result, there is a critical need to find novel antineoplastic agents that have the potential to improve the outcome in this difficult illness.

\section{Administration of Anti-angiogenic Agents in Epithelial Ovarian Cancer Preclinical Rationale}

As the fundamental biologic process of new blood vessel formation (angiogenesis) has been well-documented to play a crucial role in normal reproductive physiology, it should perhaps not come as a surprise that laboratory investigative efforts have demonstrated the strong association between high levels of expression (within the tumor or circulation) of vascular endothelial growth factors (VEGFs) and poor survival outcomes in ovarian cancer. ${ }^{4-7}$

These provocative observations subsequently led to an intensive search for antineoplastic agents that might interfere with the growth promoting effects of these potent angiogenic factors in ovarian cancer. As a result, a number of drugs with anti-angiogenic properties have been explored in clinical trials in the management of this malignancy. ${ }^{?}$

\section{Nonrandomized Experience with Bevacizumab in the Treatment of Ovarian Cancer}

Bevacizumab, a monoclonal antibody inhibitor of VEGF, has demonstrated activity in a number of tumor types and specific clinical settings, and is widely employed in routine cancer management. ${ }^{7}$

Several nonrandomized phase II studies have confirmed both the biologic and clinical activity of single agent bevacizumab (15-20\% response rate) in previously treated patients with ovarian cancer. ${ }^{8,9}$ As anticipated, the most common side effect was hypertension, but in one experience a disquieting incidence (10\%) of bowel perforation was observed. ${ }^{9}$

This outcome has been speculated to have resulted from the recognized negative impact of anti-angiogenic agents on the tissue-repair process, particularly in the setting of carcinomatosis. Furthermore, the observation has led to the suggestion that bevacizumab should be administered with great caution (if at all) in the presence of extensive intra-abdominal disease or when there is evidence of bowel dysfunction (e.g. symptoms of partial small bowel obstruction).

Additional reported retrospective experiences and phase II trial data have confirmed both the safety and potential utility of bevacizumab when combined with cytotoxic agents in ovarian cancer. However, in the absence of randomized study data, the specific contribution of the anti-angiogenic (or of the cytotoxic) to a particular suggested favorable outcome remained unknown. ${ }^{10-12}$ 
Table 1: Phase III Randomized Trials of Cytotoxic Chemotherapy plus Bevacizumab in Epithelial Ovarian Cancer

\begin{tabular}{|c|c|c|}
\hline & $\begin{array}{l}\text { PFS } \\
\text { (Median, in months) }\end{array}$ & $\begin{array}{l}\text { Overall Survival } \\
\text { (Median, in months) }\end{array}$ \\
\hline \multicolumn{3}{|l|}{ GOG 218 (front-line treatment) } \\
\hline $\begin{array}{l}\text { Carboplatin/paclitaxel + ('placebo' } \\
\text { during chemotherapy and } \\
\text { maintenance) }\end{array}$ & 10.3 & 39.3 \\
\hline $\begin{array}{l}\text { Carboplatin/paclitaxel + } \\
\text { bevacizumab (during chemotherapy) } \\
\text { + ('placebo' during maintenance) }\end{array}$ & 11.2 & 38.7 \\
\hline $\begin{array}{l}\text { Carboplatin/paclitaxel + } \\
\text { bevacizumab (during chemotherapy } \\
\text { and maintenance) }\end{array}$ & $14.1(p<0.001)$ & 39.7 \\
\hline \multicolumn{3}{|l|}{ ICON 7 (front-line treatment) } \\
\hline Carboplatin/paclitaxel & 22.4 & - \\
\hline Carboplatin/paclitaxel + bevacizumab & $24.1(p=0.04)$ & - \\
\hline \multicolumn{3}{|c|}{ OCEANS TRIAL (platinum-sensitive recurrent disease) } \\
\hline Carboplatin/gemcitabine & 8.4 & 35.2 \\
\hline $\begin{array}{l}\text { Carboplatin/gemcitabine } \\
+ \text { bevacizumab }\end{array}$ & $12.4(p<0.0001)$ & 33.3 \\
\hline \multicolumn{3}{|c|}{ AURELIA TRIAL (platinum-resistant disease) } \\
\hline $\begin{array}{l}\text { Pegylated liposomal doxorubicin, } \\
\text { or weekly paclitaxel, or topotecan }\end{array}$ & 3.4 & - \\
\hline $\begin{array}{l}\text { Pegylated liposomal doxorubicin, } \\
\text { or weekly paclitaxel or topotecan } \\
\text { + bevacizumab }\end{array}$ & $6.7(p<0.001)$ & - \\
\hline$\overline{P F S}=$ progression-free survival. & & \\
\hline
\end{tabular}

\begin{tabular}{|c|c|c|}
\hline & GOG 218 & ICON 7 \\
\hline Placebo control & Yes & No \\
\hline Dose of bevacizumab & 15 mg/kg & $7.5 \mathrm{mg} / \mathrm{kg}$ \\
\hline $\begin{array}{l}\text { Duration of bevacizumab (or } \\
\text { 'placebo') after completion } \\
\text { of cytotoxic agents }\end{array}$ & $\begin{array}{l}\text { Approximately } \\
18 \text { months }\end{array}$ & $\begin{array}{l}\text { Approximately } \\
12 \text { months }\end{array}$ \\
\hline $\begin{array}{l}\text { Disease stages included } \\
\text { in study }\end{array}$ & $\begin{array}{l}\text { Stage III (incompletely } \\
\text { resected), stage IV }\end{array}$ & $\begin{array}{l}\text { High risk, early } \\
\text { stage, stages IIB-IV }\end{array}$ \\
\hline Study arms & $\begin{array}{l}\text { Three (including bevacizumab } \\
\text { during chemotherapy only, } \\
\text { and during chemotherapy } \\
\text { plus single-agent } \\
\text { 'maintenance') }\end{array}$ & $\begin{array}{l}\text { Two (bevacizumab } \\
\text { given with } \\
\text { chemotherapy and } \\
\text { single-agent } \\
\text { 'maintenance' }\end{array}$ \\
\hline
\end{tabular}

\section{Phase III Randomized Trial of Primary Chemotherapy of Ovarian Cancer With or Without Bevacizumab}

Two large, well-conducted multi-institutional phase III randomized trials that examined a role for bevacizumab in the front-line management (after initial cytoreductive surgery) of epithelial ovarian cancer have now been reported (see Table 1). 13,14 GOG 218 was conducted by the Gynecologic Oncology Group (US) ${ }^{13}$, while ICON-7 was undertaken by an international consortium of investigators. ${ }^{14}$ While the studies differed in several important details (see Table 2) they reached similar conclusions that the addition of bevacizumab to primary carboplatin plus paclitaxel chemotherapy improves progressionfree survival (PFS) in this clinical setting.

Although the question has not been completely settled, OS does not appear to have been improved in the population of women who received bevacizumab within the two trials. The reasons for the inability to demonstrate an improvement in OS despite the statistically significant impact of therapy on PFS has been extensively discussed (and debated), but likely relates to the multiple biologically and clinically active antineoplastic agents (including bevacizumab) administered to patients after they had completed treatment on the particular study, and the favorable impact of such therapy on the population of individuals who were randomized to, and initially received, the 'underperforming control' regimen. ${ }^{15}$ Again, in these studies the major toxicity of bevacizumab was hypertension and other well-recognized vascular effects of the anti-angiogenic agent. Importantly, the incidence of bowel perforations observed in these trials was lower than that seen in the phase II second-line study noted above. ${ }^{13,14}$

Questions remain unanswered in terms of a potential role for bevacizumab in the primary treatment of ovarian cancer, including: (a) the optimal dose level (15 mg/kg versus $7.5 \mathrm{mg} / \mathrm{kg}$ ) to be delivered; (b) the duration of treatment in responding/'stable'patients who are tolerating the 'maintenance' strategy; and (c) whether all (or most) of the benefits observed relate solely to 'maintenance' drug administration (following the completion of chemotherapy) versus an alternative hypothesis that the agent also potentiates the favorable effects of the cytotoxic drugs and should be delivered simultaneously with the chemotherapy.

\section{Phase III Randomized Trial in Recurrent Potentially Platinum-sensitive Ovarian Cancer}

In the OCEANS trial, patients who developed recurrent ovarian cancer at least 6 months following the completion of primary platinum-based chemotherapy were randomized to receive a previously established 'standard-of-care' regimen of carboplatin plus gemcitabine or a program of these two cytotoxic agents plus bevacizumab (see Table 1). ${ }^{16}$ In contrast to the previously discussed primary chemotherapy trials, while the chemotherapy was delivered for six to 10 cycles, the bevacizumab was continued until disease progression. Of note, this was also a double-blind placebo-controlled trial. There were no unexpected safety signals in this study, and the incidence of bowel perforations resulting from bevacizumab delivery in this population was not considered to be problematic.

The study revealed the addition of bevacizumab improved PFS, but not OS. Again, this outcome likely resulted from the administration of multiple clinically active antineoplastic agents (including bevacizumab) to patients following the completion of treatment on this study. ${ }^{15}$

\section{Phase III Trial of Bevacizumab in Platinum-resistant Ovarian Cancer}

Finally, we come to perhaps the most provocative of the phase III trials that have examined a potential role for bevacizumab in ovarian cancer management. In A Study of Avastin (Bevacizumab) Added to Chemotherapy in Patients With Platinum-resistant Ovarian Cancer (AURELIA), patients were randomized to one of three single cytotoxic agents (pegylated liposomal doxorubicin, topotecan, or weekly paclitaxel) with known (but limited) activity in platinum-resistant ovarian cancer (evidence of 
disease progression within 6 months from the last dose of platinumbased chemotherapy) (see Table 1) ${ }^{17}$. The decision to employ one of these cytotoxic agents was made by the investigator. Patients randomized to the 'experimental arm' received one of the three drugs plus bevacizumab.

While the final results of this trial have yet to be reported (at the time of publication of this review article) the addition of bevacizumab was associated with a statistically significant improvement in PFS compared with chemotherapy alone. Data on OS remain immature. The impact of this treatment on a PFS endpoint is highly noteworthy as this is the first randomized phase III trial in platinum-resistant ovarian cancer to demonstrate that any experimental regimen can improve PFS compared with a 'standard-of-care' control arm.

As with the previous studies, the toxicity profile of bevacizumab was similar to that observed in other settings. In addition, while the number of patients treated with a specific chemotherapy agent (plus or minus bevacizumab) was insufficient to draw any definitive conclusions, the addition of the antiangiogenic appeared to be equally beneficial independent of the selected cytotoxic employed.

\section{Conclusions}

Based on the existing evidence it is difficult, in the opinion of this author, to fail to conclude that bevacizumab has highly relevant biologic and clinical activity in epithelial ovarian cancer. Further, assuming careful consideration is given to individual patients who should likely not receive the agent (e.g. evidence of extensive intra-abdominal carcinomatosis with symptomatic and/or radiographic evidence of partial bowel obstruction), the toxicity profile of the drug in all of the settings tested in these excellent phase III clinical trials appears to be quite acceptable.

Unfortunately, despite this observation, it remains difficult today to define an optimal strategy for the use of bevacizumab in epithelial ovarian cancer. This 'difficulty' is magnified substantially when one considers the current cost of bevacizumab, particularly if contemplating 18+ months of therapy in a woman who may actually be 'cured' of her malignancy or perhaps not progress for 'several years' following the completion of cytotoxic treatment. Finally, there is even the provocative (but potentially 'expensive question') of whether the continued administration of bevacizumab along with multiple cytotoxic chemotherapy regimens might result in the best clinical outcome.

For completeness, it should also be noted that trials demonstrating the favorable impact of paclitaxel administered on a weekly schedule as primary therapy ${ }^{18}$ or monthly as a 'maintenance' approach ${ }^{19}$ in the management of ovarian cancer raise the question of whether a far less expensive 'anti-angiogenic' strategy may produce similar results to bevacizumab (or other anti-angiogenic agents). Of course, the toxicity profile of paclitaxel and bevacizumab differ substantially, and the matter of 'efficacy' can only be addressed through the conduct of appropriately designed and conducted randomized trials.
1. Hennessy B, Coleman RL, Markman M, Ovarian cancer, Lancet, 2009;374:1371-82.

2. Markman M, Ovarian cancer survival: Steady improvement, despite rhetoric to the contrary, Current Oncology Reports, 2013;15(5):433-5

3. Ferara $\mathrm{N}$, Role of vascular endothelial growth factor in regulation of physiological angiogenesis, Am J Physio, 2001;280:1358-66.

4. Raspollini MR, Amunni G, Villanucci A, et al., Prognostic significance of microvessel density and vascular endothelial growth factor expression in advanced serious carcinoma, Int J Gynecol Cancer, 2004;14:815-23.

5. Smerdel MP, Steffensen KD, Waldstrom M, et al., The predictive value of serum VEGF in multiresistant ovarian cancer patients treated with bevacizumab, Gynecol Oncol, 2010;118:167-71.

6. Yreated with bevacizumab, Gynecol Oncol, 2010,118.167-71 angiogenesis-related genes and progression of human ovarian carcinoma in nude mice, J Natl Cancer Inst, 1998;90:447-54.

7. Burger RA, Overview of anti-angiogenic agents in development for ovarian cancer, Gynecol Oncol, 2011;121:230-38.

8. Burger RA, Sill M, Monk BJ, et al., Phase II trial of bevacizumab in persistent or recurrent epithelial ovarian cancer or primary peritoneal cancer: A Gynecologic Oncology Group study, J Clin
Oncol, 2007;25:5165-71.

9. Cannistra SA, Matulonis UA, Person RT, et al., Phase II study of bevacizumab in patients with platinum-resistant ovarian cancer or peritoneal serous cancer, J Clin Oncol, 2007;25:5180-86.

10. Garcia AA, Hirte H, Fleming G, et al., Phase II clinical trial of bevacizumab and low-dose metronomic oral cyclophosphamide in recurrent ovarian cancer: A trial of the California, Chicago and Princess Margaret Hospital Phase II Consortia, J Clin Oncol, 2008;26:76-82

11. Wright JD, Hagemann A, Rader JS, et al., Bevacizumab combination therapy in recurrent, platinum-refractory, epithelial ovarian carcinoma: A retrospective analysis, Cancer, 2006;107:83-9

12. Micha JP, Goldstein BH, Rettenmaier MA, et al., A phase II study of outpatient first-line paclitaxel, carboplatin, and bevacizumab for advanced-stage epithelial ovarian, peritoneal, and fallopian for advanced-stage epithelial ovarian, peritoneal,

13. Burger RA, Brady MF, Bookman MA, et al., Incorporation of bevacizumab in the primary treatment of ovarian cancer, N Engl J Med, 2011;365:2473-83.

14. Perren TJ, Swart AM, Pfisterer J, et al., A phase 3 trial of bevacizumab in ovarian cancer, N Engl J Med, 2011;365:2484-96.
15. Broglio KR, Berry DA, Detecting an overall survival benefit that is derived from progression-free survival, J Natl Cancer Inst, 2009;101:1642-49.

16. Aghajanian C, Blank SV, Goff BA, et al., OCEANS: A randomized, double-blind, placebo-controlled phase III trial of chemotherapy with or without bevacizumab in patients with platinum-sensitive recurrent epithelial ovarian, primary peritoneal, or fallopian tube recurrent epithelial ovarian, primary pe
cancer, J Clin Oncol, 2012;30:2039-45.

17. Pujade-Lauraine E, Hilpert F, Weber B, et al., AURELIA: A randomized phase III trial evaluating bevacizumab plus chemotherapy for platinum-resistant ovarian cancer, J Clin Oncol, 2012;30:(Suppl. LBA5002).

18. Katsumata $\mathrm{N}$, Yasuda $\mathrm{M}$, Takahashi $\mathrm{F}$, et al., Dose-dense paclitaxel once a week in combination with carboplatin every 3-weeks for advanced ovarian cancer: A phase 3, open-label, randomized controlled trial, Lancet, 2009;374:1331-8.

19. Markman M, Liu PY, Wilczynski S, et al., Phase III randomized trial of 12 versus 3 months of maintenance paclitaxel in patients with advanced ovarian cancer after complete response to platinum and paclitaxel-based chemotherapy: A Southwest Oncology Group and Gynecologic Oncology Group trial, J Clin Oncol 2003;21:2460-65. 